\title{
The relationship between microvessel density, proliferative activity and expression of vascular endothelial growth factor-A and its receptors in eutopic endometrium and endometriotic lesions
}

\author{
V Bourlev, N Volkov, S Pavlovitch, N Lets, A Larsson ${ }^{1}$ and M Olovsson ${ }^{2}$ \\ Research Centre of Obstetrics, Gynaecology and Perinatology, Russian Academy of the Medical Sciences, Moscow, \\ Russia, ${ }^{1}$ Department of Medical Sciences, Section for Clinical Chemistry and ${ }^{2}$ Department of Women's and Children's \\ Health, The Centre for Reproductive Biology in Uppsala, Uppsala University, S-751 85 Uppsala, Sweden
}

Correspondence should be addressed to M Olovsson; Email: matts.olovsson@kbh.uu.se

\begin{abstract}
Studies were performed to elucidate the possible relationship between microvessel density, proliferative activity and angiogenesis in eutopic endometrium from women with and without endometriosis and peritoneal endometriotic lesions. The question whether changes in these parameters in endometriotic lesions were reflected by the level of vascular endothelial growth factor-A (VEGF-A) in serum and peritoneal fluid was also studied. Biopsy specimens of both eutopic endometrium and peritoneal endometriotic lesions from women with endometriosis $(n=25)$ as well as eutopic endometrium from women without endometriosis $(n=14)$ were analysed immunohistochemically regarding microvessel density, proliferative activity, and expression of VEGF-A and its receptors vascular endothelial growth factor receptors 1 and 2 (VEGFR-1 and VEGFR-2) in stroma, glands and blood vessels. The VEGF-A concentration was measured in peritoneal fluid and serum. Secretory phase eutopic endometrium from women with endometriosis had significantly higher microvessel density, expression of VEGF-A in glandular epithelium and VEGFR-2 in endometrial blood vessels than those from women without endometriosis. Endometriotic lesions with high proliferative activity had a higher microvessel density and showed higher vascular expression of VEGFR-2 as well as being accompanied by higher levels of VEGF-A in peritoneal fluid and serum, compared with lesions with low proliferative activity. In conclusion, there seems to be a dysregulation of angiogenic activity in the eutopic endometrium of women with endometriosis and endometriotic lesions with high proliferative activity were accompanied by higher local angiogenic activity and higher levels of VEGF in serum and peritoneal fluid.
\end{abstract}

Reproduction (2006) 132 501-509

\section{Introduction}

Endometriosis is a common gynaecological disease, occurring in about $10 \%$ of all women and up to $60-80 \%$ of women with infertility problems or pelvic pain (Goldman \& Cramer 1990, Koninckx et al. 1991). Despite a number of theories concerning the origin of endometriosis (Vinatier et al. 2001), the precise pathogenetic mechanisms remain enigmatic. Proposed mechanisms include genetic predisposition (Stefansson et al. 2002, Simpson 2003), involvement of the immune system (Berkkanoglu \& Arici 2003), changes in the peritoneal fluid, peritoneum and endometrium, and retrograde menstruation (Valle 2002). The ability of endometrial fragments to implant is of particular interest in the pathogenesis of peritoneal endometriosis. A number of studies, both in vivo and in vitro, indicate that endometrial fragments in the menstrual fluid might survive and adhere to an intact peritoneal surface (Witz et al. 2001). Little is known about the regulation of growth of the ectopic endometrium and the recruitment of blood vessels to the endometriotic lesions. It is known, however, that downregulation of ovarian activity by use of contraceptive pills, gestagens or $\mathrm{GnRH}$ analogues usually reduces the activity of endometriotic lesions and relieves the pain (Rice 2002). The effects of these treatments are thought to be due to a reduction in the levels of oestradiol in the pelvic region (DeMayo et al. 2002).

It has been shown that eutopic endometrium of women with endometriosis differ from that of healthy women without the disease (Garrido et al. 2002). This includes aromatase activity in the eutopic endometrium from women with moderate to severe endometriosis, but not in those of disease-free women (Noble et al. 1996). There is also a higher VEGF-A content in the secretory phase 
eutopic glandular epithelium (Donnez et al. 1998) and an elevated endothelial cell proliferation in women with endometriosis (Wingfield et al. 1995), compared with those without. Accumulated data thus suggest that eutopic endometrium of women with endometriosis behaves differently from the endometrium of women without the disease.

An adequate degree of vascularization is a major prerequisite for normal endometrial function (Nisolle et al. 1993). It has also been shown that neovascularization is necessary for the survival of tumour implants larger than 2-3 $\mathrm{mm}^{3}$ (Folkman 1995) and endometriotic lesions recruit blood vessels by inducing angiogenesis (Taylor et al. 2002). Several angiogenic growth factors, such as vascular endothelial growth factor-A (VEGF-A), are present in human ectopic and eutopic endometrium (McLaren 2000, Möller et al. 2001). VEGF-A is considered important both for angiogenesis in general and endometrial angiogenesis (Smith 1998, Papetti \& Herman 2002). VEGF-A exists in several isoforms, all of which are potent stimulators of angiogenesis (Robinson \& Stringer 2001). Alternative splicing of a single gene generates six isoforms of VEGF-A composed of 121, 145, 165, 183, 189 and 206 amino acid residues, respectively. The larger isoforms are cell-associated or bound to extracellular matrix components, while $\mathrm{VEGF}_{121}$ and VEGF $_{165}$ are freely diffusible in the extracellular environment and might therefore be identifiable in biological fluids, such as peritoneal fluid or blood. VEGF-A exerts its biological effects by binding to either of its two tyrosine kinase receptors, vascular endothelial growth factor receptors 1 or 2 (VEGFR-1 and VEGFR-2). Among the most important regulators of VEGF gene expression are hypoxia, sex steroids and different cytokines (Shifren et al. 1996, Sharkey et al. 2000). VEGF-A has been detected in serum and peritoneal fluid from patients with endometriosis (McLaren et al. 1996a, Gagne et al. 2003).

Proliferating cells can be identified by studying the nuclear or perinuclear expression of $\mathrm{Ki}-67$, a protein that is expressed during all phases of the cell cycle except the $\mathrm{G}_{\mathrm{o}}$ phase. A number of studies have shown good correlation between expression of $\mathrm{Ki}-67$ and the number of mitotic cells (Ueda et al. 1989). It has been reported that the mitotic activity changes in both eutopic and ectopic endometrium during the menstrual cycle (Nisolle et al. 1993, Jones et al. 1995). Recently, it has also been shown that there are differences in the mitotic activity between red, black and white endometriotic lesions and the proliferative activity seems to correlate with the content of VEGF in the peritoneal fluid (Khan et al. 2004).

We hypothesise that a high microvessel density should be reflected by a high endothelial cell mitotic activity and also a high expression of the angiogenic growth factor VEGF-A and its two receptors. The main objective of the present study therefore was to examine the relationship between microvessel density, mitotic activity in blood vessels and expression of VEGF-A and its receptors VEGFR-1 and VEGFR-2 in eutopic endometrium from women with and without endometriosis and in peritoneal endometriotic lesions. We also wanted to determine whether differences between lesions regarding local proliferative activity could be detected by analysing VEGF in serum and peritoneal fluid.

\section{Materials and Methods}

\section{Patient recruitment}

Twenty-five patients of 22-44 years (mean 32.7) with peritoneal endometriosis, and 14 patients of 20-37 years (mean 29.0) without endometriosis, were recruited. The diagnosis of peritoneal endometriosis was confirmed by laparoscopy and histological examination of peritoneal biopsy specimens collected from areas with suspected lesions. The extent of the endometriosis was scored according to the revised American Society for Reproductive Medicine Classification (American Society for Reproductive Medicine 1996) and was equal to stage II-III in all cases of the endometriosis group.

Patients without endometriosis were recruited among women undergoing laparoscopic sterilization. The women were assessed as being in the proliferative (13 with and 6 without endometriosis) or secretory (12 with and 8 without endometriosis) phase of the menstrual cycle on the basis of the menstrual cycle pattern, histological examination of the eutopic endometrium (Noyes et al. 1975) and the serum concentrations of oestradiol and progesterone. Hormone analysis was performed with a method based on enzyme-amplified chemiluminescence (Immulite, Diagnostic Products Corporation, CA, USA) in accordance with the supplier's instructions. The mean serum concentrations of progesterone and oestradiol were $5.8 \pm 0.5 \mathrm{nM}(3.6-7.0 \mathrm{nM})$ and $307.3 \mathrm{pM}(87-581 \mathrm{pM})$ respectively in the proliferative phase and $23.0 \mathrm{nM}(9.5-41.8 \mathrm{nM})$ and $337.9 \mathrm{pM}(91.0-709.0 \mathrm{pM})$ respectively in the secretory phase. Patients with irregular menstrual cycles or gynaecological disorders other than endometriosis and those who had received hormonal treatment within the last 3 months were excluded. The Ethics Committee at the Research Centre for Obstetrics, Gynaecology and Perinatology in Moscow approved the study protocol and informed consent was obtained from all patients. The protocol of the study was also approved by the Ethics Committee of Uppsala University.

\section{Collection of tissue specimens, serum and peritoneal fluid}

Samples of eutopic endometrium were obtained prior to laparoscopy by sharp curettage of the corpus of the uterine cavity of both healthy controls and women with endometriosis. Samples of ectopic endometrium were obtained during laparoscopy by carefully removing at 
least three suspected peritoneal endometriotic lesions from each patient with laparoscopically verified pelvic endometriosis. The majority of the collected endometriotic specimens appeared mainly as black during laparoscopy. Of the collected lesions were $44 \%$ black, $52 \%$ black and partly red or white and $4 \%$ red. Each biopsy specimen was divided into two parts: one was prepared for histopathological investigation and the other was snap-frozen in liquid nitrogen and stored at $-70{ }^{\circ} \mathrm{C}$ until analysed. Histopathologically, all endometrial biopsy samples appeared normal and all samples of ectopic endometrium contained endometrial glandular epithelium surrounded by stromal tissue.

Venous blood samples were collected in the morning prior to surgery. Peritoneal fluid samples were collected by aspiration during surgery if there was no contamination with blood. Both the serum and the peritoneal fluid samples were cooled with ice water and centrifuged at $1500 \mathrm{~g}$ for $10 \mathrm{~min}$ in a refrigerated centrifuge within 30-60 min after collection. Supernatants of peritoneal fluid and serum samples were stored at $-70{ }^{\circ} \mathrm{C}$ until analysed.

\section{Immunohistochemical staining}

Immunostaining was performed by applying the avidin-biotin peroxidase complex (ABC) method. Serial cryosections of $5 \mu \mathrm{m}$ were prepared, air-dried, and fixed in Zamboni's fixative ( $\mathrm{pH}$ 7.3). Endogenous peroxidase activity was blocked with $0.6 \% \mathrm{H}_{2} \mathrm{O}_{2}$ in distilled water. Unspecific binding was blocked by incubating the sections with $2 \%$ BSA in PBS ( $\mathrm{pH} 7.4$ ) for 30 min. The sections were incubated with primary antibody for $1 \mathrm{~h}$ at $37^{\circ} \mathrm{C}$ and rinsed three times for 5 min each in PBS prior to incubation with secondary antibody for $60 \mathrm{~min}$ at room temperature. Sections were then rinsed for three times, 5 min each in PBS and incubated with avidin-biotin complex (ABC Elite Kit, Vector Laboratories, CA, USA) for $30 \mathrm{~min}$ at room temperature. Specific staining was visualized by applying diaminobenzidine substrate kit (Vector Laboratories) for 3-5 min. After washing, the sections were counterstained with Mayer's haematoxylin, dehydrated and mounted in mounting medium (Pertex, Histolab products AB, Gothenburg, Sweden). Series of all samples and controls were run at least twice.

Image analysis was used to count the number of blood vessels and proliferating cells (Ki-67) and as an aid in grading the intensities of staining for VEGF-A and its receptors. Basically, five to ten non-overlapping, randomly chosen pictures of the endometrial sections were taken at $400 \times$ magnification with a JVC 3-CCD video camera attached to a light field microscope (Nikon Labophot, Nikon, Tokyo, Japan). Images were digitised in a PC and subsequently assessed using the image analysis software program Image pro-plus (Media Cybernetics, Massachusetts, CA, USA).

\section{Microvessel density}

With a few modifications, the measurements were made according to a technique described earlier (Goddard et al. 2002). The primary antibody used was a monoclonal anti-human CD31 (DAKO A/S, Glostrup, Denmark) at $0.3 \mu \mathrm{g} / \mathrm{ml}$. Relevant class-matched IgG was used as negative control. As secondary antibody, we used a biotinylated horse anti-mouse antibody at $1.0 \mu \mathrm{g} / \mathrm{ml}$ (Vector laboratories, Burlingame, CA, USA). Positive controls were performed by staining human placenta and human lymph node that have a known expression of the corresponding epitope. Five randomly chosen fields measuring $0.109 \mathrm{~mm}^{2}$ were counted, the mean values calculated, and the results expressed as the number of microvessels per millimetre square.

\section{Proliferative activity}

Monoclonal mouse anti-Ki-67 (MIB-1, Immunotech, Marseille, France; diluted 1:300) was used as primary antibody and biotinylated horse anti-mouse antibody (Vector Laboratories) as secondary. Immunohistochemical staining of cryosections of a human ovarian carcinoma served as positive control. The number of $\mathrm{Ki}-67$-positive cells was evaluated separately in stroma, glands and blood vessels. A proliferative index (PI) was calculated as the percentage of cells that were $\mathrm{Ki}-67$ positive.

Angiogenic growth factor VEGF-A and its receptors VEGFR-1 and VEGFR-2

The primary antibodies used were polyclonal mouse anti-VEGF (AB-2, PC-37, Oncogene Science, Inc., Cambridge, MA, USA; 1:500), rabbit anti-VEGFR-1 (c-17, sc-316, Santa Cruz Biotechnology, CA, USA; 1:500) and a monoclonal mouse anti-VEGFR-2 (IgG1, A-3, sc-6251, Santa Cruz Biotechnology; 1:500). As secondary antibody, either horse anti-mouse $\operatorname{IgG}(1: 200)$ or goat anti-rabbit IgG (1:200, Vector Laboratories) was used. Positive controls were performed for all antibodies by staining tissues with known expression of the corresponding epitopes (human placenta and human lymph node). Omission of the primary antibody served as negative control. Non-specific staining was not detected.

The intensity of the staining was evaluated by two independent observers ( $\mathrm{V} \mathrm{B}$ and $\mathrm{S} \mathrm{P}$ ) and graded as 0 , when comparable to the negative control; 1 , when weak (clearly visible but no more); 2 , when between weak and strong and 3, when strong.

\section{Quantitative determination of VEGF-A in serum and peritoneal fluid}

For analysis of samples, commercially available ELISA kits for VEGF-A (DVE00, R\&D Systems, Minneapolis, $M N$, USA) were used according to the supplier's 
instructions. The lower detection limit for VEGF-A was set at $5.0 \mathrm{pg} / \mathrm{ml}$.

\section{Statistical analysis}

Values are reported as mean \pm S.E.M. Unpaired two-tailed $t$-tests or Wilcoxon rank-sum tests were used for comparing results. For analysis, SPSS for Windows (Release 10.0.7) was used. The level of statistical significance was set at $P<0.05$.

\section{Results}

\section{Microvessel density in eutopic and ectopic endometrium}

The data are presented in Table 1. The eutopic endometrium from women without endometriosis had an average microvessel density of $229 / \mathrm{mm}^{2}$, with no significant difference between proliferative and secretory phases of the menstrual cycle. In women with endometriosis, the eutopic endometrium had a higher microvessel density in the secretory than the proliferative menstrual phase. Secretory phase eutopic endometrium from women with endometriosis had a higher microvessel density than that from women without endometriosis. Ectopic endometrium (endometriotic lesions) showed the opposite pattern, with a higher microvessel density in the proliferative than in the secretory phase. In the proliferative phase, ectopic endometrium with high proliferative activity had a higher microvessel density than that with low proliferative activity.

\section{Proliferative activity in eutopic and ectopic endometrium}

In eutopic endometrium (Table 2) from women without endometriosis, the proliferative index (PI) was higher in glandular epithelium during the proliferative phase compared with the secretory phase. No such difference was seen for stromal and vascular cells.
In eutopic endometrium from women with endometriosis, the proliferative index (PI) again was higher in glandular epithelium during the proliferative phase compared with the secretory phase. Vascular cells, however, had a significantly higher PI during the secretory phase compared with the proliferative phase.

In ectopic endometrium (Table 3 ), the PI varied from almost 0 to a fairly high value in both stromal and glandular epithelial cells. The three or more samples from each patient showed the same degree of proliferative activity and the mean PI value was calculated for each patient. The patients were subsequently divided into two groups based on PI in the glandular epithelial cells. Lesions with $\mathrm{PI}<1$ were denoted as having low proliferative activity $(n=8)$, and those with $\mathrm{PI}$ above 1 , as having high proliferative activity $(n=17)$. Lesions classified as having low proliferative activity had a significantly lower $\mathrm{PI}$ in both the stroma $(P<0.001)$ and the glandular epithelial cells $(P<0.0001)$ than those with higher proliferative activity. There was, however, no significant difference in PI for blood vessels between women with lesions with low and high proliferative activities.

\section{Expression of VEGF-A and its receptors in eutopic and ectopic endometrium}

In eutopic endometrium from women without endometriosis, the expression of VEGF-A was higher in glandular epithelium during the proliferative than the secretory menstrual phase (Table 2). This difference was not seen in eutopic endometrium from women with endometriosis. There were no menstrual cycle phase-related differences for VEGFR-1 and VEGFR-2 in eutopic endometrium. Concerning the expression of VEGF-A, it was higher in endometrial glandular epithelial cells from women with endometriosis than those without, during the secretory phase. The expression of VEGFR-1 and VEGFR-2 was lower in stromal cells from women with endometriosis in both proliferative and secretory menstrual phases, while the expression of VEGFR-2 was

Table 1 Microvessel density (MVD) expressed as the number of intersecting microvessels per millimetre squared.

\begin{tabular}{|c|c|c|c|c|}
\hline Types of endometrium & All patients 1 & Proliferative phase 2 & Secretory phase 3 & $P<0.05$ \\
\hline A & $\begin{array}{c}228.9 \pm 72.7 \\
n=14\end{array}$ & $\begin{array}{c}192.1 \pm 37.9 \\
n=6\end{array}$ & $\begin{array}{c}243.9 \pm 80.8 \\
n=8\end{array}$ & \\
\hline B & $\begin{array}{c}315.3 \pm 196.5 \\
n=25\end{array}$ & $\begin{array}{c}152.8 \pm 25.2 \\
n=13\end{array}$ & $\begin{array}{c}452.8 \pm 170.1 \\
n=12\end{array}$ & $2-3$ \\
\hline $\mathrm{C}$ & $\begin{array}{c}225.1 \pm 154.2 \\
n=25\end{array}$ & $\begin{array}{c}295.6 \pm 172.7 \\
n=13\end{array}$ & $\begin{array}{c}132.2 \pm 40.9 \\
n=12\end{array}$ & $2-3$ \\
\hline $\mathrm{D}$ & $\begin{array}{c}261.1 \pm 87.3 \\
n=17\end{array}$ & $\begin{array}{c}321.1 \pm 190.1 \\
n=8\end{array}$ & $\begin{array}{c}134.1 \pm 48.3 \\
n=9\end{array}$ & $2-3$ \\
\hline E & $\begin{array}{c}161.6 \pm 57.6 \\
n=8\end{array}$ & $\begin{array}{c}225.9 \pm 98.8 \\
n=5\end{array}$ & $\begin{array}{c}127.1 \pm 48.4 \\
n=3\end{array}$ & \\
\hline$P<0.05$ of importance & D-E & $\mathrm{C}-\mathrm{E} ; \mathrm{D}-\mathrm{E}$ & $A-B$ & \\
\hline
\end{tabular}

(A) Eutopic endometrium from women without endometriosis. (B-E) Biopsy specimens from women with endometriosis: (B) eutopic endometrium, (C) ectopic endometrium, (D) ectopic endometrium with high proliferative activity, (E) ectopic endometrium with low proliferative activity. $n$, Number of patients. Data are expressed as mean values \pm s.D. 
Table 2 Immunohistochemical staining of eutopic endometrium from women without $(\mathrm{N})$ and with (E) pelvic endometriosis.

\begin{tabular}{|c|c|c|c|c|c|c|c|c|}
\hline & & \multicolumn{3}{|c|}{ Proliferative menstrual phase $(\mathrm{N}) n=6(\mathrm{E}) n=13$} & \multicolumn{3}{|c|}{ Secretory menstrual phase $(\mathrm{N}) n=8(\mathrm{E}) n=12$} & \multirow[b]{2}{*}{$\begin{array}{l}P \text { values of } \\
\text { importance }\end{array}$} \\
\hline & & Stromal cells 1 & $\begin{array}{c}\text { Glandular } \\
\text { epithelium } 2\end{array}$ & Blood vessels 3 & Stromal cells 4 & $\begin{array}{l}\text { Glandular } \\
\text { epithelium } 5\end{array}$ & Blood vessels 6 & \\
\hline \multirow[t]{2}{*}{ Ki-67 } & $\mathrm{N}$ & $10.9 \pm 4.8$ & $25.0 \pm 3.8$ & $1.3 \pm 0.2$ & $10.5 \pm 4.8$ & $12.9 \pm 5.2$ & $3.5 \pm 0.5$ & $2-5<0.05$ \\
\hline & $\mathrm{E}$ & $8.4 \pm 1.4$ & $27.9 \pm 3.1$ & $1.8 \pm 0.4$ & $9.6 \pm 1.8$ & $15.1 \pm 3.5$ & $3.9 \pm 0.6$ & $\begin{array}{l}2-5<0.05 \\
3-6<0.05\end{array}$ \\
\hline$P$ value & & NS & NS & NS & NS & NS & NS & \\
\hline \multirow[t]{2}{*}{ VEGF-A } & $\mathrm{N}$ & $1.2 \pm 0.3$ & $2.3 \pm 0.3$ & $0.2 \pm 0.2$ & $0.5 \pm 0.3$ & $0.5 \pm 0.3$ & $0.2 \pm 0.2$ & $2-5<0.01$ \\
\hline & $\mathrm{E}$ & $0.8 \pm 0.1$ & $2 \pm 0.2$ & $0.3 \pm 0.2$ & $0.5 \pm 0.1$ & $1.5 \pm 0.2$ & $0.4 \pm 0.2$ & \\
\hline$P$ value & & $N \bar{S}$ & $\overline{N S}$ & $\overline{N S}$ & $N \bar{S}$ & $<0.01$ & NS & \\
\hline \multirow[t]{2}{*}{ VEGFR-1 } & $\mathrm{N}$ & $1.2 \pm 0.2$ & $2.0 \pm 0.3$ & $1.2 \pm 0.7$ & $1.2 \pm 0.2$ & $2.0 \pm 0.2$ & $1.2 \pm 0.6$ & \\
\hline & $\mathrm{E}$ & $0.4+0.2$ & $1.8+0.2$ & $1.1+0.5$ & $0.5+0.2$ & $1.8+0.2$ & $1.3+0.4$ & \\
\hline$P$ value & & $<0.01$ & NS & NS & $<0.01$ & $\overline{N S}$ & $\overline{N S}$ & \\
\hline \multirow[t]{2}{*}{ VEGFR-2 } & $\mathrm{N}$ & $1.2 \pm 0.2$ & $2.4 \pm 0.6$ & $1.6 \pm 0.5$ & $1.2 \pm 0.2$ & $2.5 \pm 0.2$ & $1.3 \pm 0.2$ & \\
\hline & $\mathrm{E}$ & $0.7 \pm 0.2$ & $1.8 \pm 0.2$ & $1.8 \pm 0.4$ & $0.6 \pm 0.2$ & $1.8 \pm 0.2$ & $1.9 \pm 0.2$ & \\
\hline$P$ value & & $<0.01$ & $\overline{N S}$ & $\overline{N S}$ & $<0.01$ & $<\overline{0.05}$ & $<\overline{0.05}$ & \\
\hline
\end{tabular}

Proliferative index is expressed as percentage of cells expressing Ki-67. Staining intensities for VEGF-A and its receptors VEGFR-1 and VEGFR-2 in endometrial stroma, glands and blood vessels were graded from 0 to 3. NS, not statistically significant. Data are expressed as mean values \pm s.D.

higher in blood vessels of patients with endometriosis in the secretory phase.

Table 3 and Fig. 1 present results of samples of ectopic endometrium with either high or low proliferative activity in glandular epithelial cells. There were no significant differences in the proliferative activity in blood vessels between these two groups. Samples with high proliferative activity in glandular epithelial cells showed higher expression of VEGF-A in both stromal $(P<0.01)$ and epithelial $(P<0.001)$ cells than samples with low proliferative activity. The expression of VEGFR1 was similar in samples with high and low proliferative activities. Samples with high proliferative activity in glandular epithelial cells displayed higher expression of VEGFR-2 in stromal $(P<0.05)$, glandular epithelial $(P<$ $0.01)$ and vascular $(P<0.05)$ cells than those with low proliferative activity.

\section{Serum and peritoneal fluid concentrations of VEGF-A}

Women with endometriosis had a higher content of VEGF$A$ in peritoneal fluid $(282 \pm 65 \mathrm{pg} / \mathrm{ml})$ compared with women without endometriosis $(125 \pm 17 \mathrm{pg} / \mathrm{ml} ; P<0.05)$ in the secretory phase. There was no difference in the serum content of VEGF between women with and without endometriosis. There were no significant differences in VEGF content in serum and peritoneal fluid between proliferative and secretory menstrual phases.

Women with endometriotic lesions showing high proliferative activity had a higher level of VEGF-A in both peritoneal fluid and serum than women with endometriotic lesions showing low proliferative activity $(287 \pm 46$ vs $140 \pm 17, P<0.01$ and $136 \pm 24$ vs $61 \pm 17$, $P<0.02$ respectively).

\section{Discussion}

This study has comprised an integrated analysis of the proliferative activity, microvessel density and expression of the angiogenic growth factor VEGF and its receptors VEGFR-1 and VEGFR-2 in biopsy samples of eutopic and ectopic endometrium. Further, the concentration of VEGF-A was measured in both peritoneal fluid and serum from the same patients. We found a relation

Table 3 Immunohistochemical staining of ectopic endometrium.

\begin{tabular}{|c|c|c|c|c|c|c|c|}
\hline & \multicolumn{3}{|c|}{ High proliferative activity $(n=17)$} & \multicolumn{3}{|c|}{ Low proliferative activity $(n=8)$} & \multirow[b]{2}{*}{$\begin{array}{l}P \text { values of } \\
\text { importance }\end{array}$} \\
\hline & Stromal cells 1 & $\begin{array}{l}\text { Glandular } \\
\text { epithelium } 2\end{array}$ & Blood vessels 3 & Stromal cells 4 & $\begin{array}{l}\text { Glandular } \\
\text { epithelium } 5\end{array}$ & Blood vessels 6 & \\
\hline Ki-67 & $3.8 \pm 3.3$ & $8.9 \pm 6.4$ & $1.8 \pm 1.0$ & $0.9 \pm 0.9$ & $0.5 \pm 0.3$ & $1.3 \pm 0.6$ & $\begin{array}{l}1-4<0.0001 \\
2-5<0.001\end{array}$ \\
\hline VEGF-A & $0.8 \pm 0.1$ & $1.7 \pm 0.2$ & $0.1 \pm 0.1$ & $0.5 \pm 0.1$ & $0.7 \pm 0.1$ & $0.4 \pm 0.4$ & $\begin{array}{l}1-4<0.01 \\
2-5<0.001\end{array}$ \\
\hline VEGFR-1 & $0.7 \pm 0.1$ & $1.4 \pm 0.2$ & $1.75 \pm 1.0$ & $0.7 \pm 0.1$ & $1.2 \pm 0.2$ & $0.75 \pm 0.4$ & \\
\hline VEGFR-2 & $0.8 \pm 0.1$ & $1.9 \pm 0.1$ & $2.14 \pm 0.6$ & $0.5 \pm 0.1$ & $0.8 \pm 0.2$ & $1.25 \pm 0.3$ & $\begin{array}{l}1-4<0.05 \\
2-5<0.01 \\
3-6<0.05\end{array}$ \\
\hline
\end{tabular}

The samples were sub-grouped according to their proliferative activity in glandular epithelial cells. Proliferative index is expressed as percentage of cells expressing Ki-67. Staining intensities for VEGF-A and its receptors VEGFR-1 and VEGFR-2 in endometrial stroma, glands and blood vessels were graded from 0 to 3 . Data are expressed as mean values \pm s.D. 


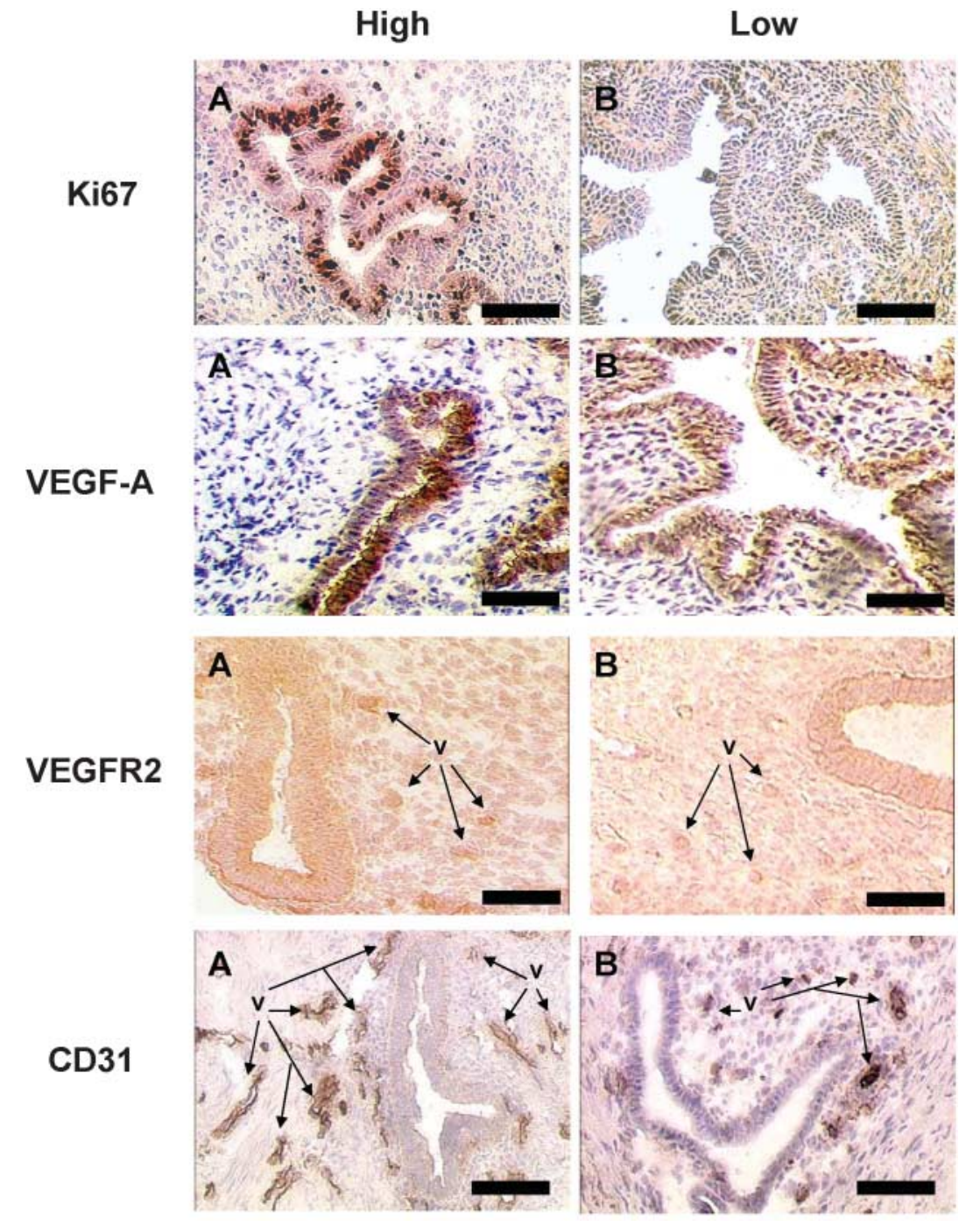

Figure 1 Immunohistochemical staining of ectopic endometrium. Proliferating cells were identified by staining for $\mathrm{Ki}-67$. The angiogenic growth factor VEGF-A and its receptor VEGFR-2 were found in stroma, glands and blood vessels (v). Blood vessels were recognised by staining for $C D 31$. Pictures on the left (A) represent samples with a high mitotic activity in the glandular epithelial cells and those on the right (B) represent samples with a low proliferative activity. Scale bar is $25 \mu \mathrm{m}$. between a higher microvessel density in the secretory phase eutopic endometrium from women with endometriosis with a higher expression of VEGF-A in secretory phase glandular epithelium and VEGFR-2 in endometrial blood vessels. We were also able to show a correlation between the proliferative and the angiogenic activity in endometriotic lesions and this was also reflected by the VEGF-A content in serum and peritoneal fluid.

In our study, we used lesions where the majority appeared black or mainly black during laparoscopy. These black lesions are considered to be more established and mature compared with the red ones (Nisolle et al. 1993, Brosens 1994). However, it has been shown that black lesions have lower proliferative activity than the red ones (Nisolle et al. 1993, Khan et al. 2004). In spite of the histological homogeneity in our material, we found large differences in cell mitotic activity in both stroma and glandular epithelium, ranging from no detectable mitoses to numerous ones. The stromal mitotic activity was higher in samples with high mitotic activity in the glandular epithelium, but the main difference in mitotic activity was attributable to the glandular epithelial cells. On the basis of this finding, we sub-grouped the samples into those with high and low mitotic activities in the glandular epithelial cells. PI was chosen as a cut when the samples were sub-grouped because it was required to have a group of samples with very low PI to compare with those with a significantly higher PI.

Angiogenesis is believed to be important for the establishment and the survival of endometriotic lesions as well as for the eutopic endometrium. A number of studies on women with endometriosis have shown differences from healthy controls both in the peritoneal fluid composition, and the eutopic and ectopic endometrium that relate to the regulation of angiogenesis (McLaren et al. 1996b, Healy et al. 1998, McLaren 
2000, Sharkey et al. 2000, Garrido et al. 2002). VEGF-A seems to be one of the most important angiogenic growth factors in the regulation of angiogenesis in general and probably also in both eutopic and ectopic endometrium ( $\mathrm{Li}$ et al. 1994, McLaren et al. 1996b, Shifren et al. 1996, Torry et al. 1996, Donnez et al. 1998, Möller et al. 2001). We can show that VEGF-A and its receptors VEGFR-1 and VEGFR-2 are present in both eutopic and ectopic endometrium, and their relation to microvessel density and proliferative activity will be discussed later.

Regarding the microvessel density in eutopic endometrium from women without endometriosis, our data were consistent with the previous reports (Rogers et al. 1993, Goodger \& Rogers 1994, Charnock-Jones et al. 2000, Möller 2004) that the number of intersecting microvessels per millimetre squared seems to be fairly constant during the menstrual cycle (Table 1). The significantly higher microvessel density in the secretory phase eutopic endometrium from women with endometriosis, compared with women without endometriosis, was reflected by a significantly higher expression of VEGF-A in glandular epithelium and of VEGFR-2 in blood vessels as well as a higher level of VEGF-A in peritoneal fluid. Thus, there seems to be a more proangiogenic situation in eutopic endometrium from women with endometriosis compared with women without the disease. We were also able to demonstrate a significantly higher proliferative activity in blood vessels during the secretory, compared with the proliferative menstrual phase in women with endometriosis. It has previously been shown that the VEGF-A content was significantly higher in the eutopic glandular epithelium of endometriotic patients during the secretory phase (Donnez et al. 1998) and that the peritoneal fluid level of VEGF-A is elevated in women with endometriosis, with the highest levels during the secretory phase (McLaren et al. 1996a). The higher microvessel density in the secretory phase eutopic endometrium from women with endometriosis might be due to a higher production of VEGF-A within the eutopic endometrium (McLaren et al. 1996b) or an extensive endometrial exposure of VEGF-A that is produced and contained in the peritoneal fluid. There are two possible ways by which peritoneal fluid VEGF$A$ can reach the eutopic endometrium and stimulate endometrial angiogenesis: (1) by transport of peritoneal fluid via the uterine tubes to the uterine cavity and (2) through the local pelvic network of lymph and blood vessels. There is also a possibility that substances other than VEGF-A in the peritoneal fluid might stimulate endometrial angiogenesis. In any case, there seems to be increased angiogenic activity in the secretory phase eutopic endometrium in women with endometriosis. A widely accepted theory concerning the pathogenesis of endometriosis includes retrograde menstruation and implantation of endometrial fragments on peritoneal surfaces (Sampson 1927). Such endometrial implants will soon depend on the formation of new blood vessels through angiogenesis. It has been proposed that high microvessel density and angiogenic activity in endometrial fragments seeded into the peritoneal cavity might be of advantage during the establishment and growth of the resulting peritoneal lesions, as the large amount of microvessels and endothelial cells would be able to take part in neovascularization (Healy et al. 1998). The high vascular density and increased proangiogenic properties found in eutopic secretory phase endometrium from women with endometriosis might thus at least be a supportive factor in the pathogenesis of endometriosis.

Ectopic endometrium showed a higher microvessel density in the proliferative phase, in contrast to the finding in eutopic endometrium. Since we found no differences in the expression of VEGF-A or its receptors (data not shown), or in the content of VEGF-A in peritoneal fluid or serum, between the proliferative and secretory menstrual phases, other reasons for this may need to be sought. Possible explanatory mechanisms include the ectopic site of growth, the presence of endogenous aromatase activity in the endometriotic lesions (Bulun et al. 2001) and the continuous exposure to peritoneal fluid with its content of pro-inflammatory and pro-angiogenic substances, factors that might override or bias the control of proliferation and function that is normally exerted by the ovarian sex steroid hormones. In a previous study, no difference was found in the microvessel density of endometriotic lesions between the different phases of the menstrual cycle (Matsuzaki et al. 1998).

It has previously been shown that red lesions with high mitotic activity also had higher microvessel density than white lesions with lower proliferative activity (Nisolle et al. 1993). We found similar differences between ectopic endometrium with high and low proliferative activities in epithelial and stromal cells, where the microvessel density was higher in samples with high proliferative activity in the proliferative, but not the secretory phase of the menstrual cycle (Table 1). We have now been able to show that endometriotic lesions with high proliferative activity are also accompanied by high angiogenic activity, as reflected by higher expression of VEGF-A in stroma and glandular epithelium and of VEGFR-2 in blood vessels (Table 3), as well as higher levels of VEGF-A in both serum and peritoneal fluid. Moreover, the mitotic activity in blood vessels seemed to be higher in lesions with high proliferative activity, but the difference was not statistically significant. This may not be surprising, however, since it has been shown that angiogenic activity in eutopic endometrium assessed in terms of the number of proliferating endothelial cells is fairly constant during the menstrual cycle (Rogers et al. 1993), although there are reports on peaks of blood vessel formation during the 
menstrual cycle (Gargett et al. 1999, Gargett \& Rogers 2001). Several studies also indicate that endometrial angiogenesis does not occur according to the classical mechanism with sprouting of new capillary blood vessels from maternal blood vessels. It has been suggested that sprouting is of minor importance, since markers for and formations of sprouts have not been observed in eutopic human endometrium (Rogers \& Gargett 1998). It is believed, rather, that angiogenesis in eutopic endometrium occurs mainly through vessel elongation and to some extent also via intussusceptive microvascular growth and incorporation of circulating endothelial progenitor cells into the growing blood vessels (Gambino et al. 2002). However, it is not known whether the same mechanisms are responsible for angiogenesis in ectopic endometrium. It has previously been shown that higher the concentration of VEGF in the peritoneal fluid is, the more advanced is the endometriosis (Mahnke et al. 2000) and that the amount of vascularization in and around the endometriotic lesion correlates with the mitotic activity within the lesion (Nisolle et al. 1993).

We thus found a correlation between high mitotic activity in the endometriotic lesions and high levels of VEGF in serum and peritoneal fluid. It has previously been shown that there is a correlation between the mitotic activity in endometriotic lesions and the serum level of CA-125 in women with stage III-IV peritoneal endometriosis (Toki et al. 2000). Similarly, a correlation has been observed between the mitotic activity in endometriotic lesions and the peritoneal fluid levels of hepatocyte growth factor, VEGF, interleukin-6 and monocyte chemotactic protein-1 (Khan et al. 2004). The clinical implications of high mitotic activity in endometriotic lesions remain unclear, but this finding might be relevant for the intensity of pain or the question of whether the lesions are growing on the peritoneal surface or are infiltrative. Diagnosis of endometriosis by laboratory testing of VEGF is not possible according to our results, as also has been concluded by others (Gagne et al. 2003, Bedaiwy \& Falcone 2004, Potlog-Nahari et al. 2004). Like others (Gagne et al. 2003), we, in serum, found no differences in VEGF levels between women with and without endometriosis. An analysis of the serum level of VEGF might, however, be a useful tool to determine whether endometriotic lesions have high or low proliferative activity, a test that might be meaningful when attempting to monitor a response to treatment.

Taken together, our results show that there seems to be a dysregulation of angiogenic activity in the eutopic endometrium of women with endometriosis and a correlation between the proliferative and angiogenic activities in endometriotic lesions, which was also reflected by the VEGF-A content in serum and peritoneal fluid. An abnormal control of endometrial angiogenesis in women with endometriosis might have an impact on bleeding control and fertility.

\section{Acknowledgements}

The authors thank Dr Denis Stygar, The Research Centre of Obstetrics, Gynaecology and Perinatology, Moscow, for his assistance in collecting the samples and Björn Möller, Margareta Nordling and Ulla Geifalk, The Department of Women's and Children's Health, Uppsala University, for their technical assistance. This investigation was supported by grants from the Russian Academy of Medical Sciences, the Royal Swedish Academy of Sciences, the Uppsala Family Planning Foundation, the Swedish Society of Medicine and the Swedish Research Council (Project no. 8683). The authors declare that there is no conflict of interest that would prejudice the impartiality of this scientific work.

\section{References}

American Society for Reproductive Medicine 1996 Revised American society for reproductive medicine classification of endometriosis. Fertility and Sterility 67 817-821.

Bedaiwy MA \& Falcone T 2004 Laboratory testing for endometriosis. Clinica Chimica Acta 340 41-56.

Berkkanoglu M \& Arici A 2003 Immunology and endometriosis. American Journal of Reproductive Immunology 50 48-59.

Brosens IA 1994 Is mild endometriosis a disease? Is mild endometriosis a progressive disease? Human Reproduction 9 2209-2211.

Bulun SE, Yang S, Fang Z, Gurates B, Tamura M, Zhou J \& Sebastian S 2001 Role of aromatase in endometrial disease. Journal of Steroid Biochemistry and Molecular Biology 79 19-25.

Charnock-Jones DS, Macpherson AM, Archer DF, Leslie S, Makkink WK, Sharkey AM \& Smith SK 2000 The effect of progestins on vascular endothelial growth factor, oestrogen receptor and progesterone receptor immunoreactivity and endothelial cell density in human endometrium. Human Reproduction 15 85-95.

DeMayo FJ, Zhao B, Takamoto N \& Tsai SY 2002 Mechanisms of action of estrogen and progesterone. Annals of the New York Academy of Sciences 955 48-59.

Donnez J, Smoes P, Gillerot S, Casanas-Roux F \& Nisolle M 1998 Vascular endothelial growth factor (VEGF) in endometriosis. Human Reproduction 13 1686-1690.

Folkman J 1995 Clinical applications of research in angiogenesis. New England Journal of Medicine 333 1757-1764.

Gagne D, Page M, Robitaille G, Hugo P \& Gosselin D 2003 Levels of vascular endothelial growth factor (VEGF) in serum of patients with endometriosis. Human Reproduction 18 1674-1680.

Gambino LS, Wreford NG, Bertram JF, Dockery P, Lederman F \& Rogers PA 2002 Angiogenesis occurs by vessel elongation in proliferative phase human endometrium. Human Reproduction $\mathbf{1 7}$ 1199-1206.

Gargett CE \& Rogers PA 2001 Human endometrial angiogenesis. Reproduction 121 181-186.

Gargett CE, Lederman FL, Lau TM, Taylor NH \& Rogers PA 1999 Lack of correlation between vascular endothelial growth factor production and endothelial cell proliferation in the human endometrium. Human Reproduction 14 2080-2088.

Garrido N, Navarro J, Garcia-Velasco J, Remohi J, Pellicer A \& Simon C 2002 The endometrium versus embryonic quality in endometriosisrelated infertility. Human Reproduction Update 8 95-103.

Goddard JC, Sutton CD, Furness PN, Kockelbergh RC \& O’Byrne KJ 2002 A computer image analysis system for microvessel measurement in solid tumours. Angiogenesis 5 15-20. 
Goodger AM \& Rogers PA 1994 Endometrial endothelial cell proliferation during the menstrual cycle. Human Reproduction 9 399-405.

Goldman MB \& Cramer DW 1990 The epidemiology of endometriosis. Progress in Clinical and Biological Research 323 15-31.

Healy DL, Rogers PAW, Hii L \& Wingfield M 1998 Angiogenesis: a new theory for endometriosis. Human Reproduction Update 4 736-740.

Jones RK, Bulmer JN \& Searle RF 1995 Immunohistochemical characterization of proliferation, oestrogen receptor and progesterone receptor expression in endometriosis: comparison of eutopic and ectopic endometrium with normal cycling endometrium. Human Reproduction 10 3272-3279.

Khan KN, Masuzaki H, Fujishita A, Kitajima M, Sekine I \& Ishimaru T 2004 Higher activity by opaque endometriotic lesions than in nonopaque lesions. Acta Obstetricia et Gynecologica Scandinavica 83 375-382.

Koninckx PR, Meuleman C, Demeyere S, Lesaffre E \& Cornille FJ 1991 Suggestive evidence that pelvic endometriosis is a progressive disease, whereas deeply infiltrating endometriosis is associated with pelvic pain. Fertility and Sterility $\mathbf{5 5}$ 759-765.

Li XF, Gregory J \& Ahmed A 1994 Immunolocalisation of vascular endothelial growth factor in human endometrium. Growth Factors 11 277-282.

Mahnke JL, Dawood MY \& Huang J-C 2000 Vascular endothelial growth factor and interleukin- 6 in peritoneal fluid of women with endometriosis. Fertility and Sterility 73 166-170.

Matsuzaki S, Canis M, Darcha C, Dechelotte P, Pouly JL \& Bruhat MA 1998 Angiogenesis in endometriosis. Gynecologic and Obstetric Investigation 46 111-115.

McLaren J 2000 Vascular endothelial growth factor and endometriotic angiogenesis. Human Reproduction Update 6 45-55.

McLaren J, Prentice A, Charnock-Jones DS \& Smith SK 1996a Vascular endothelial growth factor (VEGF) concentrations are elevated in peritoneal fluid of women with endometriosis. Human Reproduction 11 220-223.

McLaren J, Prentice A, Charnock-Jones DS, Millican SA, Müller KH, Sharkey AM \& Smith SK 1996b Vascular endothelial growth factor is produced by peritoneal fluid macrophages in endometriosis and is regulated by ovarian steroids. Journal of Clinical Investigation 98 482-489.

Möller B 2004 Human endometrial angiogenesis. An immunohistochemical study of the endometrial expression of angiogenic growth factors and their corresponding receptors. Acta Universitatis Upsaliensis. Comprehensive Summaries of Uppsala Dissertations from the Faculty of Medicine 131550 (Uppsala. ISBN 91-554-5831-9).

Möller B, Rasmussen C, Lindblom B \& Olovsson M 2001 Expression of the angiogenic growth factors VEGF, FGF-2, EGF and their receptors in normal human endometrium during the menstrual cycle. Molecular Human Reproduction 5 65-72.

Nisolle M, Casanas-Roux F, Anaf V, Mine JM \& Donnez J 1993 Morphometric study of the stromal vascularization in peritoneal endometriosis. Fertility and Sterility 59 681-684.

Noble LS, Simpson ER, Johns A \& Bulun SE 1996 Aromatase expression in endometriosis. Journal of Clinical Endocrinology and Metabolism 81 174-179.

Noyes RW, Hertig AT \& Rock J 1975 Dating the endometrial biopsy. American Journal of Obstetrics and Gynecology 122 262-263.

Papetti M \& Herman IM 2002 Mechanisms of normal and tumorderived angiogenesis. American Journal of Physiology. Cell Physiology 282 947-970.

Potlog-Nahari C, Stratton P, Winkel C, Widra E, Sinaii N, Connors S \& Nieman LK 2004 Urine vascular endothelial growth factor-A is not a useful marker for endometriosis. Fertility and Sterility 81 1507-1512.

Rice VM 2002 Conventional medical therapies for endometriosis. Annals of the New York Academy of Sciences 955 343-352.
Robinson CJ \& Stringer SE 2001 The splice variants of vascular endothelial growth factor (VEGF) and their receptors. Journal of Cell Science 114 853-865.

Rogers PAW \& Gargett CE 1998 Endometrial angiogenesis. Angiogenesis 2 287-294.

Rogers PA, Au CL \& Affandi B 1993 Endometrial microvessel density during the normal menstrual cycle and following exposure to longterm levonorgestrel. Human Reproduction 8 1396-1404.

Sampson JA 1927 Peritoneal endometriosis due to the menstrual dissemination of endometrial tissue into the peritoneal cavity. American Journal of Obstetrics and Gynecology 14 422-469.

Sharkey AM, Day K, McPherson A, Malik S, Licence D, Smith SK \& Charnock-Jones DS 2000 Vascular endothelial growth factor expression in human endometrium is regulated by hypoxia. The Journal of Clinical Endocrinology and Metabolism 85 402-409.

Shifren JL, Tseng JF, Zaloudek CJ, Ryan IP, Meng YG, Ferrara N, Jaffe RB \& Taylor RN 1996 Ovarian steroid regulation of vascular endothelial growth factor in the human endometrium: implications for angiogenesis during the menstrual cycle and in the pathogenesis of endometriosis. Journal of Clinical Endocrinology and Metabolism 81 3112-3118.

Simpson JL 2003 Heritability and candidate genes for endometriosis. Reproductive Biomedicine Online 7 162-169.

Smith SK 1998 Angiogenesis, vascular endothelial growth factor and the endometrium. Human Reproduction Update 4 509-519.

Stefansson H, Geirsson RT, Steinthorsdottir V, Jonsson H, Manolescu A, Kong A, Ingsdottir G, Gulcher J \& Stefansson K 2002 Genetic factors contribute to the risk of developing endometriosis. Human Reproduction 17 555-559.

Toki T, Kubota J, Lu X \& Nakayama K 2000 Immunohistochemical analysis of CA125, CA19-9, and Ki-67 in stage III or IV endometriosis: positive correlation between serum CA125 level and endometriotic epithelial cell proliferation. Acta Obstetricia et Gynecologica Scandinavica 79 771-776.

Taylor RN, Lebovic DI \& Mueller MD 2002 Angiogenic factors in endometriosis. Annals of the New York Academy of Sciences 955 89-100.

Torry DS, Holt VJ, Keenan JA, Harris G, Caudle MR \& Torry RJ 1996 Vascular endothelial growth factor expression in cycling human endometrium. Fertility and Sterility 66 72-79.

Ueda T, Aozasa K, Tsujimoto M, Ohsawa M, Uchida A, Aoki Y, Ono K \& Matsumoto K 1989 Prognostic significance of ki-67 immunoreactivity in soft tissue sarcomas. Cancer 63 1607-1611.

Valle RF 2002 Endometriosis: current concepts and therapy. International Journal of Gynaecology and Obstetrics 78 107-119.

Vinatier D, Orazi G, Cosson M \& Dufor P 2001 Theories of endometriosis. European Journal of Obstetrics, Gynecology, and Reproductive Biology 96 21-34.

Wingfield M, Macpearson A, Healy DL \& Rogers PA 1995 Cell proliferation is increased in the endometrium of women with endometriosis. Fertility and Sterility 64 340-346.

Witz CA, Thomas MR, Montoya-Rodrigez IA, Nadir AS, Centonze VE \& Schenken RS 2001 Short-term culture of peritoneum explants confirms attachment of endometrium to intact peritoneal mesothelium. Fertility and Sterility 75 385-390.

Received 15 January 2006

First decision 31 March 2006

Revised manuscript received 8 May 2006

Accepted 9 June 2006 